\title{
Presence of anti-Toxocara canis antibodies and risk factors in children from the Amecameca and Chalco regions of México
}

\author{
Nadyeli Nava Cortés, Camilo Romero Núñez , Bautista Gómez Linda Guiliana, Pedro Abel Hernández García \\ and Rafael Heredia Cárdenas
}

\begin{abstract}
Background: Toxocariasis is a zoonotic disease that poses a threat to public health worldwide. This disease primarily affects children and is caused by the presence in the digestive tract of a common roundworm of dogs, Toxocara canis, or cats, Toxocara cati. Toxocara is responsible for the presentation of various syndromes in humans depending on the affected organs.

Methods: In this study, the prevalence of anti-T. canis antibodies was investigated in children aged 3-16 years from semirural populations in the municipalities of Amecameca and Chalco in México. An ELISA was used to determine the presence of anti-T. canis antibodies in blood samples.

Results: Of the 183 sera obtained for this study, 22 were positive for anti-T. canis antibodies (12.02\%). Of these, $6.50 \%$ were from males and $5.4 \%$ were from females. Risk factors were investigated and it was found that living near a cattle operation had a statistically significant association with $\left(\mathrm{Chi}^{2}=5.51\right.$ and $\left.p=0.01\right)$ and was a risk factor for $(\mathrm{OR}=4.25, p=0.02)$ seropositivity to $T$. canis. Keeping dogs with short hair $\left(\mathrm{Chi}^{2}=3.24\right.$ and $\left.p=0.07\right)$ showed a tendency toward seropositivity for $T$. canis, as did the habit of sleeping with pets (Chi ${ }^{2}=3.46$ and $p=0.06$ ).

Conclusions: Seropositivity to T. canis was confirmed in children in the Amecameca and Chalco regions of México and the risk factors were identified. These findings provide important insight into the prevalence and spread of this zoonotic parasite.
\end{abstract}

Keywords: Toxocara, Zoonotic disease, ELISA, México

\section{Background}

Dogs are associated with more than 60 zoonotic diseases worldwide, mainly by parasitic organisms, posing a serious health threat to humans $[1,2]$. Many of these intestinal parasites are eliminated as eggs, larvae or oocysts into the environment, and for this reason, contamination with the feces of dogs in private and public areas such as parks or gardens represents an important source of infection [3,4].

One of the most common infections worldwide caused by parasites is toxocariasis, a zoonotic disease [5] caused by migrating larvae of the roundworm species Toxocara

\footnotetext{
* Correspondence: mvzcamilo@yahoo.com.mx

Agricultural Sciences and Natural Resources, Amecameca University Center, Autonomous University of the State of México, Km. 2.5 Carretera

Amecameca-Ayapango, 56900 Amecameca, México
}

canis and Toxocara cati [6]. The eggs of this parasitic helminth may be accidentally ingested by humans [7] into the duodenum; once the eggs hatch, they release three-stage larvae (L3) through the action of gastric juice and digestive enzymes, which penetrate the intestinal wall, enter the bloodstream and migrate to different organs, where they lead to syndromes such as visceral larva migrans, covert larva migrans, ocular larva migrans and neurological larva migrans $[6,8]$.

Some risk factors associated with this parasite include: gender, age, socioeconomic status, close contact with domestic animals [9], ingestion of raw meat [7], poor hygiene, inadequate hand washing, nail biting, eating 


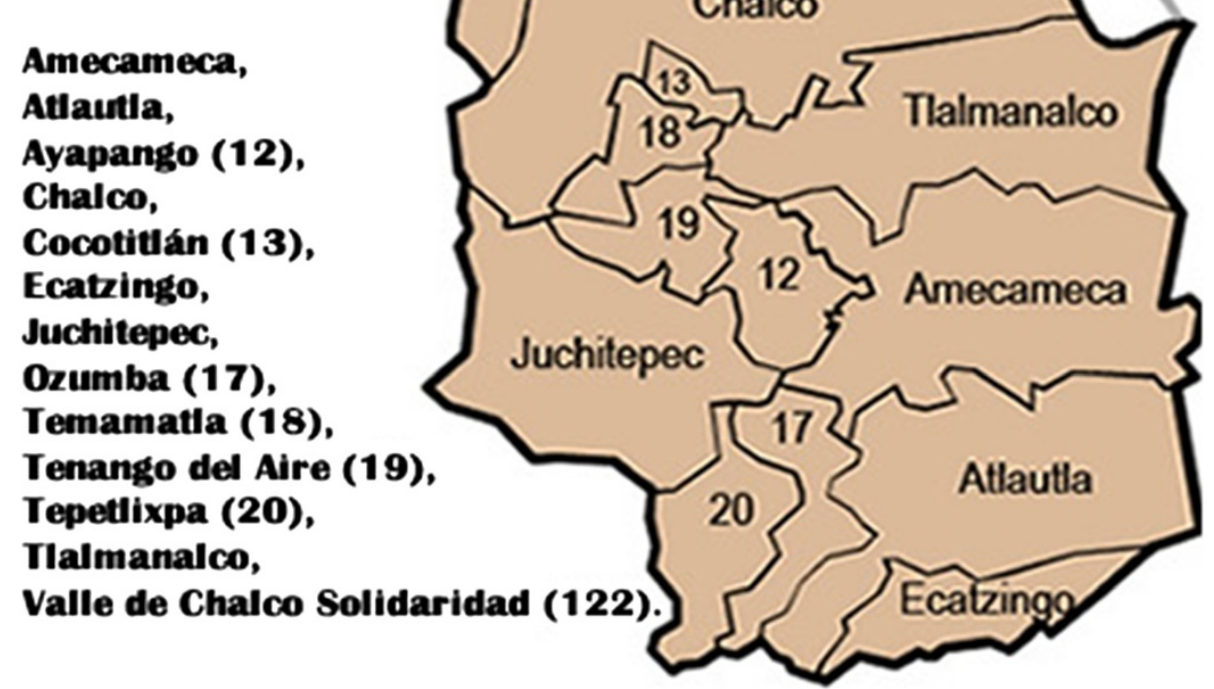

Figure 1 The location of the municipalities of Amecameca and Chalco within the State of México

contaminated food, and contact with soil or the hair from cats or dogs contaminated with eggs [4]. Children are the social group most at risk because of their recreation activities, hygiene and close relationship with pets [10].

In México, there have been studies to investigate the prevalence of $T$. canis in recreational areas, and in soil samples and the feces of stray dogs. Rates of $24 \%$ and $67.5 \%$ were obtained $[11,12]$. The high rate of contamination was thought to reflect the socioeconomic status and sanitation level of the studied region. Similar studies in other countries have also revealed a high prevalence of $T$. canis; for example, $66 \%$ prevalence in Spain and $67 \%$ prevalence in Argentina [13].

Furthermore, seroprevalence studies in children reported rates of $22.22 \%$ in México [14] compared with $86.75 \%$ in Taiwan in 2014 [15]. To investigate the public health threat caused by toxocariasis in more detail in México, in this study, circulating anti-T. canis antibodies and risk factors for $T$. canis were investigated in a semirural population in the State of México.

\section{Methods}

\section{Study population}

A total of 183 blood samples were collected from children in the municipalities of Amecameca and Chalco, México (Fig. 1), between April 2013 and February 2014. Of the children sampled, 97 were male and 86 were female, and their ages ranged from 3-16 years. Parents or guardians of minors signed an informed consent form and agreed to participate in the project, which was approved by the ethics committee of the University Center UAEM Amecameca of the Autonomous University of the State of México.

\section{Epidemiological data collection}

Epidemiological data for all of the children included in the study were obtained. These included: age, gender, height, weight, body mass index and background information regarding recent types of pathology respiratory, dermatological, neurological, allergic and ocular - and the following risk factors: eating habits and hygiene.

\section{Processing blood samples}

A 3-ml sample of blood was obtained from each participant through phlebotomy and these samples were deposited in tubes without anticoagulant and incubated at room temperature for $40 \mathrm{~min}$. Then, samples were subjected to centrifugation at $4000 \times g$ for $10 \mathrm{~min}$. The obtained sera were stored at $-20{ }^{\circ} \mathrm{C}$ according to

Table 1 Comparison of the presence of antibodies with Toxocara canis between genders

\begin{tabular}{lllll}
\hline Sex & $\begin{array}{l}\text { Positive } \\
n=22(\%)\end{array}$ & $\begin{array}{l}\text { Negative } \\
n=161(\%)\end{array}$ & Total & $p^{*}$ \\
\hline Female & $10(5.4 \%)$ & $76(41.5 \%)$ & 86 & 0.64 \\
Male & $12(6.5 \%)$ & $85(46.4 \%)$ & 97 & \\
Total & $12.02 \%$ & $87.98 \%$ & 183 & \\
\hline
\end{tabular}

*Fisher $p<0.05$ 
Table 2 Association between risk factors and the presence of antibodies against animal-related Toxocara canis

\begin{tabular}{lccccccc}
\hline Risk factor & $\begin{array}{c}\text { Positive } \\
n=22\end{array}$ & $\begin{array}{c}\text { Negative } \\
n=161\end{array}$ & Chi $^{2}$ & $p$ & OR & $p$ & Cl \\
\hline Pets at home & 8 & 75 & 0.81 & 0.36 & 0.65 & 0.36 & $0.26-1.64$ \\
Sleeping with pet & 0 & 13 & 3.46 & 0.06 & 0.24 & 0.33 & $0.01-4.25$ \\
Puppy <6 months & 2 & 17 & 0.04 & 0.83 & 0.84 & 0.83 & $0.18-3.94$ \\
Dog licks face & 2 & 4 & 2.66 & 0.10 & 3.92 & 0.12 & $0.67-22.8$ \\
Dewormed $>$ 6 months ago (pet) & 22 & 153 & 2.09 & 0.14 & 2.49 & 0.53 & $0.13-44.6$ \\
Dog with long hair $(>1 \mathrm{~cm})$ & 3 & 19 & 0.25 & 0.62 & 1.18 & 0.80 & $0.31-4.36$ \\
Dog with short hair $(<1 \mathrm{~cm})$ & 3 & 50 & 3.24 & 0.07 & 0.35 & 0.10 & $0.09-1.23$ \\
Contact with dogs or cats outside the home & 6 & 59 & 0.74 & 0.38 & 0.64 & 0.39 & $0.24-1.74$ \\
\hline
\end{tabular}

$O R$ odds ratio, $\mathrm{Cl}$ confidence interval

$p<0.05$

official Mexican guidelines for the storage of human samples (NOM-003-SSA2-1993).

\section{Serological testing of blood samples}

Serological tests were performed on the blood samples to measure anti-T. canis antibodies using a commercial ELISA kit, with a sensitivity of $87.5 \%$ and specificity of $93.3 \%$ (DIAGMEX-Toxocara ${ }^{\circ}$ SA De CV. México). The optical density of the samples was determined using a Microplate Modulus ${ }^{\oplus}$ multiplate spectrophotometer (Turner Biosystems, Kampenhout, Belgium) at a wavelength of $460 \mathrm{~nm} \mathrm{[16].} \mathrm{The} \mathrm{optical} \mathrm{density} \mathrm{cutoff} \mathrm{value}$ was 0.30 , and sera with an optical density of 0.30 or greater were considered positive.

\section{Statistical analysis}

To compare the rates of positivity between groups, Fisher's exact test [16] was applied. The variables obtained were analyzed by the Chi-square test to determine the levels of association; a value of $p<0.05$ was considered significant. The relative risk of $T$. canis antibodies was calculated from the odds ratio, with a significance of $p<0.05$. Statistical analysis was performed using $\mathrm{JMP}^{\circ} 8.0$ software (SAS Institute, Cary, NC, USA).

\section{Results}

Of the 183 sera tested, anti-T. canis antibodies were detected in $22(12.02 \%)$. No statistically significant difference was found between the prevalence of anti- $T$. canis antibodies in males and females (Table $1 ; p=0.64$ ).
Regarding risk factors, it was determined that keeping dogs with short hair $\left(\mathrm{Chi}^{2}=3.24\right.$ and $\left.p=0.07\right)$ showed a tendency toward seropositivity for $T$. canis, as did the habit of sleeping with pets $\left(\mathrm{Chi}^{2}=3.46\right.$ and $\left.p=0.06\right)$. By contrast, practicing preventive medicine and coexistence did not show a significant association (Table 2). Living near livestock farms showed a statistically significant association with $T$. canis seropositivity $\left(\mathrm{Chi}^{2}=5.51\right.$ and $p=0.01)$ and was also a risk factor for T. canis seropositivity $(\mathrm{OR}=4.25, p=0.02)$ (Table 3 ).

\section{Discussion}

In Mexicali, México, a previous study analyzing the seroprevalence of $T$. canis in children reported a rate of $10.6 \%$, less than that in the present study (12.02\%), and a higher percentage of seropositive males $(53.1 \%)$ than females, which they attributed to differences in the games played by children and their resulting close contact with the environment [10]. In other research [17], a study conducted in southeastern São Paulo, Brazil, with volunteer donors aged 19-65 years, reported seroprevalence of $8.7 \%$ and concluded that gender $(p=0.69)$ and age $(p=0.99)$ were not associated with parasitoses. These findings were in agreement with the present study in which no significant association was reported between gender and the presence of $T$. canis antibodies $(p=$ 0.64). A study by Getaz and colleagues in 2007 found no significant association between seropositivity to $T$. canis and asthma, but did identify an association with nocturnal wheezing [18].

Table 3 Risk factors associated with housing

\begin{tabular}{|c|c|c|c|c|c|c|c|}
\hline Risk factor & $\begin{array}{l}\text { Positive } \\
n=22\end{array}$ & $\begin{array}{l}\text { Negative } \\
n=161\end{array}$ & $\mathrm{Chi}^{2}$ & $p$ & OR & $p$ & $\mathrm{Cl}$ \\
\hline Frequent visits to public parks & 9 & 59 & 0.15 & 0.69 & 1.19 & 0.69 & $0.48-2.69$ \\
\hline Live near livestock farming & 4 & 8 & 5.51 & 0.01 & 4.25 & 0.02 & $1.16-15.5$ \\
\hline Garden at home & 6 & 53 & 0.28 & 0.59 & 0.76 & 0.59 & $0.28-2.06$ \\
\hline
\end{tabular}

$O R$ odds ratio, $\mathrm{Cl}$ confidence interval 
Hygiene habits, housing area and customs are factors that primarily influence the variation of seroprevalence of $T$. canis, and the risk of transmission increases with the degree of environmental pollution. Three research teams [19-21] conducted studies to identify the predisposing factors for the transmission of parasitic zoonoses and determined that pets in the bedroom, not regularly cleaning feces and no or inadequate hand washing after contact with animals posed the greatest risks of transmitting zoonotic diseases. Contamination with Toxocara spp. from the land in parks, playgrounds, gardens and beaches in urban and suburban areas is considered a critical factor for toxocariasis, as well as contact with dogs. The results of the current study showed that the potential risk factors of keeping dogs $\left(\mathrm{Chi}^{2}=3.24, p=0.07\right)$ and sleeping with dogs $\left(\mathrm{Chi}^{2}=3.46, p=0.06\right)$ showed a tendency toward seropositivity for $T$. canis but this was not a significant association. Another study of seroprevalence in children in México [14] found that frequent contact with pets was not associated with the presence of toxocariasis $\left(\mathrm{Chi}^{2}=0.80\right.$, $p=0.37$ ). A study in Argentina, however, found that contact with animals was an important risk factor for T. canis exposure in children $(\mathrm{OR}=5.02, p=0.001)$ [22]. These discrepancies may reflect differences between geographical locations or the size of characteristics of the sample populations between studies. Living near a cattle operation was found in the current study to show a statistically significant association $\left(\mathrm{Chi}^{2}=5.51, p=0.01\right)$ with the presence of anti-T. canis antibodies in children, potentially linked with the presence of stray dogs on such premises.

\section{Conclusions}

The results of this investigation revealed a seroprevalence of $12.02 \%$ for $T$. canis in children in the municipalities of Amecameca and Chalco, in the State of México. We observed a higher percentage of seropositive males than females, and attributed this to their increased activity in recreational areas. Living near livestock farms was identified as a risk factor for exposure to T. canis, as assessed by the presence of anti-T. canis antibodies.

\section{Competing interests}

The authors declare that they have no competing interests.

\section{Authors' contributions}

CRN: coordination of the study, CRN LGBG: study design, NNC: selection and handling of study subjects, CRN LGBG NNC RHC: sampling, NNC LGBG: sample processing, NNC RHC: immunoassay analysis, LGBG PAHG NNC: data analysis, RHC PAHG CRN: statistical analysis, CRN LGBG NNC RHC: writing and editing the manuscript. All authors read and approved the final manuscript.

\section{Acknowledgements}

Special thanks to everyone who contributed to the realization of this research, colleagues and friends, and participants of the same. We are grateful to the Secretary of Research and Advanced Studies at the University of the State of México and the Mexican Council of Science and Technology for supporting this study. Everyone involved in the study was aware of, and agreed with, submission of the manuscript for publication.

\section{Funding}

This study was funded by the University Autonomus of the State of México. The funding body had no role in the study design, data collection and analysis, decision to publish, or preparation of the manuscript For NNC, CRN, LGBG and RHC, funding was provided by the Secretary of Research and Advanced Studies at the University Autonomus of the State of México.

Received: 25 September 2014 Accepted: 20 May 2015

Published online: 30 May 2015

\section{References}

1. Swai ES, Kaaya EJ, Mshanga DA, Mbise EW. A survey on gastro intestinal parasites of non-descript dogs in and around Arusha Municipality, Tanzania. Int J Anim Veter Adv. 2010;2(3):63-7.

2. Khante GS, Khan LA, Boodkhe AM, Suryawanshi PR, Majed MA, Suradkan US, et al. Epidemiological survey of gastro-intestinal parasites of non-descript dogs in Nagpur City. Vet World. 2009;2(1):22-3.

3. Rinaldi L, Biggeri A, Carbone S, Musella V, Catelan D, Veneziano V, et al. Canine fecal contamination and parasitic risk in the City of Naples (Southern Italy). BMC Vet Res. 2006;2:29.

4. Despommier D. Toxocariasis: clinical aspects, epidemiology, medical ecology, and molecular aspects. Clin Microbiol Rev. 2003;16(2):265-72.

5. Rubinsky EG, Hirata CE, Yamamoto JH, Ferreira UM. Human toxocariasis: diagnosis, worldwide seroprevalences and clinical expression of the systemic and ocular forms. Ann Trop Med Parasit. 2010;104(1):3-23.

6. Wisniewska LM, Wozniakowska GT, Sobolewska DJ, Markiewicz JA, Wieczorek M. Analysis of the course and treatment of toxocariasis in children - a long-term observation. Parasitol Res. 2012;110:2363-71.

7. Choi D, Hoon LJ, Dong CC, Woon PS, Hee KS, Huh S. Toxocariasis and ingestion of raw cow liver in patients with eosinophilia. Korean J Parasitol. 2008:46(3):139-43.

8. Chen J, Min JX, Hui QS, Chun RW, Xing QZ. Canine and feline parasitic zoonoses in China. Parasit Vectors. 2012;5:152.

9. Aydenizöz ÖM, Yaǧci BB, Erat S. The investigation of Toxocara canis eggs in coats of different dog breeds as a potential transmission route in human toxocariasis. Vet Parasitol. 2008;152(1-2):94-100.

10. Tinoco GL, Barreras SA, López VG, Tamayo SAR, Quiroz RH, Melgarejo T. Seroprevalence of Larva Migrans of Toxocara canis and evaluation of associated risk factors among children in a Mexico-United States border region. Intern J Appl Res Vet Med. 2008;6(2):130-6.

11. Romero NC, García CAC, Mendoza MGD, Torres CNC, Ramírez DN. Contaminación por Toxocara spp. en parques de Tulyehualco México. Rev Cient. 2009;19(3):253-6.

12. Romero NC, Mendoza GD, Bustamante LP, Yanez S, Ramirez N. Contamination and viability of Toxocara sp. in feces collected from public parks, streets and dogs in Tejupilco at the subhumid tropic of Mexico. J Anim Vet Adv. 2010;9(23):2996-9.

13. López MA, Martin G, Chamorro MC, Alonso JM. Toxocariosis en niños de una región subtropical. Medicina. 2005;65(3):226-30.

14. Romero NC, Mendoza MGD, Yañez AS, Ponce MM, Bustamante MP. Prevalence and risk factors associated with Toxocara canis infection in children. Sci World J. 2013;2011:1-5.

15. Chung JF, Ting WC, Huei SL, Chih HW, Yung CL, Mailynn KL, et al. Seroepidemiology of Toxocara canis infection among primary school children in the capital area of the Republic of the Marshall Islands. BMC Infect Dis. 2014;14:261.

16. Roldán W, Cavero Y, Espinoza Y, Jiménez S, Ruíz C. Human toxocariasis: a seroepidemiological survey in the Amazonian City of Yurimaguas, Peru. Rev Ins Med Trop Sao Paulo. 2010;52(1):37-42.

17. Negri EC, Alvares SV, Rubinsky EG, Giuffrida R. Anti-Toxocara spp. antibodies in an adult healthy population: serosurvey and risk factors in Southeast Brazil. Asian Pac J Trop Biomed. 2013;3(3):211-6.

18. Getaz L, Samalvides F, Breña J, Torrejón D, Maguiña C. Relación entre toxocariosis y asma: estudio prospectivo en niños del Hospital Nacional Cayetano Heredia, Lima, Perú. Act Med Per. 2007;24:11-20.

19. Weese JS, Peregrine AS, Armstrong J. Occupational health and safety in small animal veterinary practice: Part II - Parasitic zoonotic diseases. Can Vet J. 2002:43:799-802.

20. Won YK, Kruszon MD, Schantz MP, Jones JL. National Seroprevalence and Risk Factors for Zoonotic Toxocara spp. Infection. Am J Trop Med Hyg. 2008;79(4):552-7. 
21. Overgaauw AM, Van ZB, Hoek CD, Fellx OY, Roelfsema J, Pinelli EC, et al. Zoonotic parasites in fecal samples and fur from dogs and cats in The Netherlands. Vet Parasitol. 2009;163(1-2):115-22.

22. Bojanich MV, Fernández G, De Los Ángeles LM, Alonso JM, Azula L.

Infección por Toxocara canis en población infantil vulnerable del noreste de Argentina. Enferm Emer. 2008;10(2):84-7.

Submit your next manuscript to BioMed Central and take full advantage of:

- Convenient online submission

- Thorough peer review

- No space constraints or color figure charges

- Immediate publication on acceptance

- Inclusion in PubMed, CAS, Scopus and Google Scholar

- Research which is freely available for redistribution 